\title{
Estructuración normativa de la relación de consumo. Criterios para una moderna aplicación de la ley de protección al consumidor
}

\section{Normative structure of the consumption relationship. Standards to modern application of the law of consumer protection}

\author{
Fabián González Cazorla* \\ Universidad Andrés Bello \\ Santiago, Chile
}

\begin{abstract}
RESUMEN: El presente artículo intenta descomponer los conceptos básicos que el legislador ha dotado como característico de la relación de consumo con la finalidad de demostrar sus aspectos deficitarios y contradictorios. Se mostrará que tanto la doctrina como la jurisprudencia extienden la noción de consumidor a otras categorías no previstas en la Ley, permitiendo, además, la configuración de una relación de consumo en supuestos que se apartan del texto normativo, beneficiando a personas que, no teniendo vínculo contractual directo con el proveedor, son merecedoras de protección jurídica en esta especial sede.
\end{abstract}

PALABRAS CLAVE: relación de consumo; acto jurídico gratuito; consumidor material.

ABSTRACT: This article it attempts to break down the basic concepts that the legislator has endowed as characteristic of the consumption relationship, in order to demonstrate its deficit and contradictory aspects. It will show that both the doctrine and jurisprudence extend the notion of consumer to other categories not provided for the Law, allowing, also, the configuration of a consumer relationship in cases that depart from the normative text, benefiting people who, having no direct contractual link with the provider, they are worthy of legal protection in this special area.

KEYWORDS: consumption relationship; gratuitous contract; material consumer.

\section{INTRODUCCIÓN}

Desde la entrada en vigencia de la Ley de Protección a los Derechos del Consumidor -en adelante LPC- en el año 1997 se han configurado una serie de cuestionamientos sobre la técnica de redacción y estructuración de la norma. Primero, porque utiliza conceptos que son en apariencia correctos pero que, en definitiva, entran en una total contradicción con la regulación completa de los derechos que se pretenden proteger. Segundo, porque el ámbito de aplicación de la ley parece ser una cuestión de difícil comprensión tanto para abogados y jueces, por lo que hay una confusión ya en su sola lectura. Y tercero, porque la ley parece considerar a la relación entre proveedor y consumidor desde una óptica eminentemente

\footnotetext{
* Abogado. Magíster en Derecho mención Derecho Privado por la Universidad de Chile. Estudiante de Doctorado en Derecho, Universidad Autónoma de Madrid. Profesor de Derecho Civil de la Facultad de Derecho de la Universidad Andrés Bello. Dirección postal: Av. Bellavista No 0121, Providencia, Santiago de Chile. Correo electrónico: fabian@ cazorla.cl
} 
privada, dejando de lado el rol que a cada uno le corresponde en la sociedad, especialmente el del primero. La mirada respecto de la relación de consumo ha sido sorpresivamente reduccionista, siendo necesaria una reinterpretación general de la LPC para su mejor comprensión, reconfiguración y aplicación práctica.

Conviene -entonces- estructurar una crítica generalizada sobre la legislación de consumo ya que, si bien parte con un afán de equiparar una situación de desequilibrio (consumidorproveedor), su contenido final sigue siendo deficitario $\mathrm{y}$ han tenido que ser la jurisprudencia y la doctrina las encargadas de dar una solución más razonable, incluso contra texto expreso.

Lo que se pretende es evidenciar los problemas conceptuales implicados en la LPC a propósito de su ámbito de aplicación, descomponiendo cada uno de los elementos que han devenido en una errada aplicación de la norma. Luego, se volverán a definir dichos conceptos atribuyéndoles un sentido acorde a una real protección al consumidor utilizando algunos criterios dogmáticos y jurisprudenciales.

Sobre la base de lo anterior, es indispensable referirse al rol que tiene el consumidor, pero mayormente el proveedor en una economía de mercado, interpretando básicamente cuál es el rol de este dentro de la sociedad a fin de atribuir y categorizar los deberes que le corresponden como comerciante de bienes o servicios. Esto, desde luego, implica analizar a cada sujeto de manera individual inserto en un contexto social y económico determinado.

\section{LA LPC, SU CARÁCTER “TUITIVO” Y LOS CONCEPTOS NORMATIVOS}

La legislación de consumo vio la luz en nuestro país después de un largo debate en el Congreso Nacional que duró aproximadamente 7 años (comprende los periodos entre 1991 y 1997) ${ }^{1}$. Se suponía que una discusión tan ardua y prolongada en el tiempo daría como fruto un texto normativo que fuera depurado y comprensible para jueces, abogados e incluso un ciudadano común. Asimismo, desde un punto de vista substancial, debía implicar un salto significativo en el reconocimiento de los derechos del consumidor para hacer frente a los abusos a que sistemáticamente se encontraba (y encuentra) muchas veces expuesto.

Pues bien, como se sabe, ni lo uno ni lo otro ocurrió. Las expectativas que los consumidores tenían con la promulgación de la norma no fueron satisfechas. Muy por el contrario, la Ley se ha tornado tortuosa y significado una serie de barreras que limitan el libre ejercicio de los derechos de los consumidores, permitiendo una actuación moderada de los proveedores sin mayor contratiempo.

La LPC se ha articulado en función de conceptos que no tienen una completa correspondencia con el tráfico actual de bienes y servicios. En general, el aspecto subjetivo y objetivo de la relación de consumo posee deficiencias graves que impiden configurar una noción amplia, lo que ha dificultado la tarea del juez al momento de interpretar la norma y aplicarla al caso concreto. En efecto, la ley, en principio, sugiere una aplicación restrictiva

\footnotetext{
${ }^{1}$ Historia de la Ley No 19.496. Primer trámite Constitucional: Cámara de Diputados, pp. 5 y ss.
} 
excluyendo hipótesis que no tengan un apego literal al texto normativo, soslayando, en consecuencia, su espíritu como norma protectora a favor del consumidor.

De este modo, resulta relevante referirse a los pilares fundamentales que inciden en la deficitaria regulación del derecho del consumo en la LPC, abordando el concepto de consumidor, que es el que más atención se le ha prestado por la doctrina y jurisprudencia.

\subsection{Noción de consumidor en la LPC}

La noción de consumidor que se ha establecido en la LPC se refiere a un sujeto que siempre tiene (o debería tener) una vinculación con el proveedor. Normalmente el vínculo está dado por la celebración de un contrato o, en términos más amplios, de un acto jurídico oneroso que implique para el proveedor un acto mercantil y uno civil para el consumidor. El artículo $1^{\circ}$ número 1 de la LPC señala que son "Consumidores o usuarios: las personas naturales o jurídicas que, en virtud de cualquier acto jurídico oneroso, adquieren, utilizan, o disfrutan, como destinatarios finales, bienes o servicios".

Por consiguiente, la configuración del concepto de consumidor pasa por una doble deficiencia que según el tenor de la ley se puede identificar: a) está vinculado contractualmente con el proveedor y b) ese contrato (o acto jurídico en general) reviste el carácter de oneroso.

En primer lugar, si se considera el factor contractual como un elemento preponderante sólo sería consumidor aquel que tenga a su haber un contrato o algún acto oneroso que lo vincule normativamente con el proveedor. Sin embargo, una interpretación de este tipo produce una evidente reducción de la noción misma de consumidor porque excluye a priori a todas las demás personas que pueden haber adquirido, utilizado o disfrutado un bien o servicio pero que no han concurrido a la celebración de ningún contrato de consumo o acto jurídico oneroso cuyos efectos le puedan ser extensivos.

Es muy probable que el legislador haya considerado que el consumidor debe estar, en algún sentido, vinculado normativamente con el proveedor, y la forma más habitual, desde luego, es el contrato. De manera que si no empleaba la noción general utilizando la fórmula de acto oneroso podrían intentar ser consumidores y acogerse a la LPC toda persona que reclame esta calidad, sin que haya sido necesario haber concurrido a su celebración.

La noción de consumidor como sujeto que celebra un acto jurídico oneroso se ve contextualizado no solamente desde el enfoque de fondo sino también desde la legitimación activa en juicio. Todavía hay sentencias que dan cuenta de una noción estrictamente legalista de consumidor excluyendo por tanto supuestos en que el destinatario final del bien o servicio que no ha celebrado acto oneroso pueda demandar los daños ocasionados por el proveedor a causa del incumplimiento de cualquiera de las obligaciones previstas en la Ley $^{2}$.

\footnotetext{
${ }^{2}$ Corte de Apelaciones de Santiago, Verdejo con Administradora Mall Plaza Vespucio S.A., 5 de octubre de 2015, Rol 998-2015, considerando 6 : "El primer inconveniente para poder asimilar esa situación a las infracciones de la Ley 19.496 es que no se acreditó en el juicio una relación de consumo entre la actora y la
} 
En síntesis, la interpretación restrictiva ${ }^{3}$ produce un evidente efecto regresivo de la norma, generando una estructura limitada de casos y situaciones que en razón de la noción legal de consumidor no permite extenderlo a otras posibles hipótesis.

Por consiguiente, el problema del concepto de consumidor -entre otras cosas- radica en suponer que existe una sola categoría aplicable a casos muy restringidos, es decir, a quien ha celebrado un acto jurídico oneroso con el proveedor.

\subsection{Noción de proveedor en la LPC}

La noción de proveedor que la LPC ha previsto para la regulación de las ventas y servicios en masa corresponde a un sujeto que está tomado de alguno de los eslabones de la cadena de producción. La ley consigna que son proveedores las personas naturales o jurídicas, de carácter público o privado, que habitualmente desarrollen actividades de producción, fabricación, importación, construcción, distribución o comercialización de bienes o de prestación de servicios a consumidores, por las que se cobre precio o tarifa (art. $1 \mathrm{n}^{\circ} 2$ LPC).

En cierto modo la LPC entrega un abanico importante de sujetos que pueden ser considerados proveedor pero en la práctica la relación bilateral suele ser distinta, sobre todo tratándose del proveedor-vendedor el cual se encuentra vinculado contractualmente con el consumidor y es, muchas veces, la cara visible a problemas de incumplimiento por defectos de la cosa cuyo origen no guarda relación con su esfera de control. La dificultad del concepto de proveedor radica fundamentalmente en la cercanía o lejanía que este tiene (o puede tener) respecto del consumidor final. Se trata entonces de hacer patente que el vendedor carga con la responsabilidad frente al consumidor por daños que este pudiera sufrir, aun cuando el origen del problema no dependa estrictamente de su voluntad.

denunciada. En efecto, ningún antecedente incorporó la denunciante para establecer el vínculo comercial que caracteriza las infracciones que contempla esa ley [...] luego, en definitiva, volvió a su casa, sin que se derive de su declaración haber efectuado en algún momento un acto mercantil en el interior del Mall, sujeto a la preceptiva en análisis"; mismo sentido, Corte de Apelaciones de Santiago, No se consigna con Cencosud Retail S.A., 12 de abril de 2016, Rol 30-2016, considerando 6 6 Corte de Apelaciones de Valparaíso, Garrido con Empresa Savilco Ltda., 29 de agosto de 2005 Rol 7693-2004, considerando $2^{\circ}$ : "Que, los hechos que se han señalado precedentemente, y que se tienen como probados, no configuran infracción al artículo 15 de la Ley de Protección al Consumidor, ni a los artículos 23 y 24, invocados en la querella y demanda civil, pues no existió relación comercial de ninguna especie entre el querellante y la denunciada, ni se acredita ella respecto de ninguno de los establecimientos de comercio del mall, dado que los espacios interiores comunes del mall son espacios de libre acceso al público independiente de cada uno de los locales comerciales allí existentes, y el hecho delictivo que se denunció ocurrió en un local comercial diferente de la cafetería, donde el denunciante se encontraba sin probar que haya efectuado un acto amparado por la Ley de Protección del Consumidor, de modo que no se produce la situación que prevé la norma invocada en la denuncia y que sirve de fundamento a la demanda civil deducida, ello sin perjuicio de la real injusticia que sufrió el denunciante como cualquier ciudadano que por error es sindicado de un delito que no ha cometido y de los derechos que pudiere invocar, pero ello ocurrió fuera del ámbito, como se ha dicho, de aplicación de la Ley que se invocó en la denuncia y en la demanda, por lo que debe ser en definitiva absuelta la denunciada y rechazada la demanda civil deducida en su contra, sin costas por haber tenido motivos plausibles para accionar".

${ }^{3}$ Por todos puede consultarse JARA AMIGO (1999) p. 54 
En la dogmática civil se ha identificado el problema del rol protagónico del vendedor frente a las demandas por daños e infracción a la LPC que intenta el consumidor. En cierto modo, el problema se genera por la redacción del conocido artículo 23 de la ley que prescribe la responsabilidad infraccional cuya hipótesis central se refiere a que el menoscabo se produzca en la venta de un bien o en la prestación de un servicio ${ }^{4}$. Así, con una interpretación restrictiva, la jurisprudencia ha impedido la posibilidad de que las acciones de infracción a la LPC junto con la de indemnización de perjuicios, a que haya lugar, puedan interponerse directa y exclusivamente en contra, por ejemplo, del fabricante de un producto, relegando el asunto mayoritariamente hacia el vendedor del mismo, quien habitualmente es una persona y/o entidad distinta.

Por otro lado, sea que fuere el vendedor, distribuidor o fabricante del bien quien debiera ser demandado no es un tema aquí porque el acento está puesto en el enfoque general que la LPC realiza respecto de la noción de proveedor, en tanto sujeto que cuenta con mayores herramientas económicas e informativas, y cuyo tratamiento no tiene correspondencia con una economía de información y fluidez como la nuestra, dejando que la actividad comercial y de emprendimiento dentro de la sociedad se desate sin contratiempos, muchas veces sin límites, lo que repercute en una posición conflictiva frente a los derechos e intereses del consumidor.

En concreto, todo lo anterior trata de evidenciar que la LPC, dada su estructura general, ha legitimado la libertad económica y el libre emprendimiento dentro de un marco constitucional y legal previamente establecido e institucionalizado pero que, al poseer algunos aspectos deficitarios en su texto normativo, produce una colisión entre la esfera de responsabilidad del proveedor con los derechos del consumidor, provocando en este último menoscabos en diversos ámbitos de su vida, particularmente por la defectuosa y restrictiva aplicación que el legislador previó para la relación de consumo.

Dichos aspectos deficitarios atañen tanto con el marco jurídico que funda la actividad económica como una posición conflictuada entre el empresario y el consumidor ${ }^{5}$ mientras que otros se refieren a la escueta y confusa estructuración de los derechos del consumidor y las obligaciones y responsabilidades que recaen sobre el proveedor.

La idea específica que está detrás es que la legislación de consumo ha permitido una actuación libre de parte del empresario y proveedor de bienes y servicios en masa, sin mayores restricciones y circunscrita la aplicación de la LPC a ciertos casos o en donde solo haya una infracción notoria. Ejemplo de estos casos son el ámbito objetivo de imposición de la LPC, las cláusulas abusivas del art. 16, el plazo de prescripción de las acciones por infracción de la ley ${ }^{6}$, las multas aplicables al proveedor.

\footnotetext{
${ }^{4}$ Véase BARRIENTOS CAMUS (2012) p. 381.

${ }^{5}$ Sobre la posición de conflicto existente entre proveedor y consumidor ALVEAR TÉLLEZ (2017) pp. 176-179 tiene una opinión crítica y señala que un análisis completo de la relación entre proveedor y consumidor no supone necesariamente una relación de tensión y conflicto sino más de bien de concurrencia y correlación pacifica cuando se comprende verdaderamente el sentido y alcance de la libertad económica.

${ }^{6}$ La Ley 21.081 modificó, entre otros, el art. 26 de la Ley 19.496 aumentando a 2 años el plazo de las acciones que persigan la responsabilidad contravencional y que inicialmente era de solo 6 meses.
} 


\subsection{La noción de relación de consumo de la LPC. Acto jurídico oneroso}

Cabe hacer presente que la LPC no otorga una conceptuación de relación de consumo sino que únicamente se refiere a las hipótesis que generalmente darían origen a la relación entre proveedor y consumidor, particularmente al acto jurídico oneroso (art. $1^{\circ}$ núm. $1 \mathrm{LPC}$ ).

La relación de consumo (también denominado acto de consumo) que se genera entre proveedor y consumidor tiene diversos matices que giran en torno a su fuente, estructura y funcionamiento. Estos elementos permiten determinar más o menos el ámbito dentro del cual opera la relación y los derechos e intereses que pueden verse involucrados de acuerdo a las circunstancias específicas.

En efecto, la fuente más habitual de esta relación es el contrato. En términos generales, este instrumento de intercambio permite a las partes poder delimitar, en algún sentido, sus intereses, derechos, expectativas y riesgos conforme a la regla contractual, es decir, a su contenido normativo ${ }^{7}$. No obstante, en el derecho del consumo si bien se considera la figura del contrato como eje principal de interacción lo importante radica en que este se integra por la ley otorgando al consumidor mayores prerrogativas y derechos que los que expresamente se hubieren pactados, convenidos y/o aceptados por este por lo que esta especial relación se erige sobre un supuesto normativo que trasciende la mera interacción de voluntades, incluyendo toda la legislación protectora existente en su favor.

La relación entre proveedor y consumidor se sustenta -mayoritariamente- sobre la base de contratos que revisten el carácter de adhesión, es decir, cuyas cláusulas no han sido negociadas por las partes sino que han sido redactadas unilateralmente por el proveedor quedándole la posibilidad al consumidor de aceptarlas o rechazarlas íntegramente ${ }^{8}$.

Este mecanismo de relación entre partes puede presentarse inicialmente como algo aparentemente injusto en cuanto impide al consumidor -la mayoría de las veces- poder conocer efectivamente las cláusulas del contrato y que repercutirán en su contenido prestacional junto con las obligaciones y responsabilidades que asume el proveedor en caso de incumplimiento, circunstancias que, en general, son desconocidas parcial o totalmente por el consumidor.

Por otro lado, frente a la relación convencional obligacional que se crea entre proveedor y consumidor también existen situaciones en las que, no estando unidas por un contrato, igualmente existe relación de consumo. Desde esta perspectiva, aquélla se presenta como una relación compleja que tiene no solamente una fuente estrictamente contractual sino también extracontractual y legal y para ello se debe distinguir entre relación de consumo en sentido restringido y amplio.

\footnotetext{
${ }^{7}$ De la Maza Gazmuri y Vidal Olivares (2014) p. 16.

${ }^{8}$ Dice López SANTA MARÍA (2010) p. 118 que el contrato de adhesión es "aquel cuyas cláusulas han sido propuestas unilateralmente por el proveedor sin que el consumidor, para celebrarlo, pueda alterar su contenido" (art. $1 \mathrm{~N}^{\mathrm{o}} 6$ LPC). En otras palabras "El contrato de adhesión o por adhesión es aquel cuyas cláusulas son dictadas o redactadas por una sola de las partes. La otra se limita a aceptarlas en bloque, adhiriendo a ellas".
} 
La relación de consumo en sentido restringido es aquella que se estructura sobre la base de los requisitos típicos consagrados en la LPC y que son la existencia de un acto jurídico oneroso entre proveedor y consumidor en virtud del cual este adquiere, utiliza o disfruta, como destinario final, bienes o servicios. Esta, podría decirse, es la conceptualización que más se ha repetido en la dogmática y en la jurisprudencia.

De hecho, el sentido restringido ha sido reproducido en sentencia de la Corte de Apelaciones de Santiago, Sánchez con Administradora de Supermercados Hiper Limitada, 16 de diciembre de 2016, Rol 1606-2016, considerando $2^{\circ}$ :

"[...], empero, ciertamente la actora [...] al no ser la propietaria de la bicicleta robada no ha sufrido perjuicio alguno en relación a la infracción del deber de seguridad en el consumo, que se denuncia bajo el amparo del artículo 3 letra d) de la Ley de Protección al Consumidor y, en consecuencia, carece de legitimación activa para accionar infraccional y civilmente. $\mathrm{Y}$ el realmente perjudicado, el señor [...], que sí es el propietario de la especie sustraída, no puede accionar civilmente en un procedimiento especial que la ley ha reservado sólo a los que participan de una relación de consumo conforme a lo que dispone el artículo 1 numero 1 de la Ley 19.496 que además de establecer el ámbito de aplicación de la ley define la calidad de consumidor o usuario y, ya está dicho, el referido actor civil no celebró contrato alguno con la demandada." (énfasis añadido).

De acuerdo con la cita, la Corte de Apelaciones entiende que solo hay relación de consumo cuando se cumplen los presupuestos establecidos en el artículo $1^{\circ}$ de la LPC, fijando el ámbito de protección del consumidor meramente a aquel que se constituye como un contratante para la adquisición de un bien o servicio ${ }^{9}$. Esta ha sido la idea constante que la jurisprudencia ha utilizado para desvirtuar algunas reclamaciones hechas por consumidores que no cumplen con el supuesto legal.

Sin embargo, en contra de lo que se viene afirmando, hoy tanto la dogmática como la jurisprudencia distan bastante de los conceptos o supuestos expresados en el artículo $1^{\circ}$ LPC ya que existe una tendencia a una noción más bien amplia de relación de consumo. En efecto, dicha relación no solamente se funda sobre una base estrictamente contractual sino que entraña la conjugación de intereses que pueden tener un origen diverso y que trascienden la mera relación onerosa entre las partes. A continuación, se exponen algunas razones que permiten ampliar la aplicación de la LPC mediante una reformulación conceptual de los tres elementos previamente desarrollados, esto es, el consumidor, el proveedor y la relación de consumo.

\section{HACIA UNA REINTERPRETACIÓN DE LOS CONCEPTOS DE LA LPC A}

\footnotetext{
${ }^{9}$ En el mismo sentido Corte de Apelaciones de Santiago: Rojas con Cencosud Retail S.A., 18 de noviembre de 2016, Rol 419-2014, especialmente considerando 3º, Lizama con Lider Domicilio Ventas y Distribución Limitada, 7 de noviembre de 2016, Rol 1273-2016, especialmente considerandos $1^{\circ}$ y $2^{\circ}$, No se consigna con no se consigna, 15 de diciembre de 2015, Rol 1508-2015, voto de minoría; Corte de Apelaciones de Valparaíso: No se consigna con no se consigna, 19 de enero de 2016, Rol 641-2015, especialmente considerandos $6^{\circ}$ y $8^{\circ}$.
} 


\section{FAVOR DEL CONSUMIDOR}

\subsection{Reformulación de la noción de consumidor. Consumidor jurídico y material}

Hasta ahora el análisis se ha centrado en la revisión del contenido normativo de la LPC y el panorama no es muy favorable al consumidor. De hecho, los tribunales han tenido serias dificultades para atribuir la calidad de consumidor a las personas que no han celebrado un acto jurídico oneroso para la adquisición de un producto o servicio o bien, contratando con el proveedor, no son destinatarios finales del mismo, y por eso se ha configurado por la doctrina la distinción entre consumidor jurídico y consumidor material ${ }^{10}$, siendo el primero quien celebra el acto jurídico y contingentemente es el destinatario final del bien o servicio y el segundo la persona que no ha celebrado un acto jurídico con el proveedor pero es el destinario final del bien o servicio usándolo o utilizándolo de algún modo ${ }^{11}$.

En la actualidad hay consenso en los autores en que la LPC protege tanto al consumidor jurídico como al material, lo que permite extender el abanico de legitimados activos para el ejercicio de determinadas acciones ${ }^{12}$.

Por ejemplo, en la venta de un producto alimenticio en mal estado que afecte la salud no solo de quien lo compró sino también de aquel que lo ingirió sin ser comprador, como cuando el padre adquiere productos de dicha naturaleza para él y para su hijo, la LPC otorgaría la acción indemnizatoria a ambos fundada en la seguridad en el consumo.

Algo similar se observa en los servicios en el caso de corte del suministro de agua potable o electricidad para una vivienda en donde no solamente resulta perjudicada aquella persona que lo contrató sino también las demás personas que habitan el inmueble y que naturalmente será el resto del grupo familiar.

Desde la perspectiva antedicha, la noción de consumidor se refiere a aquellas personas que utilizan o disfrutan de un bien o servicio, al margen de su vínculo contractual con el proveedor (oneroso o gratuito), por lo que deviene en relevante, únicamente, que sean considerados como destinatarios finales de los mismos ${ }^{13}$.

\footnotetext{
${ }^{10}$ La doctrina ya ha identificado las nociones de consumidor jurídico y material. Así ISLER SoTO (2013) p. 43 indica que "Se entiende por consumidor jurídico a aquel que interviene en el contrato de consumo, en tanto que el consumidor material se relaciona con aquella persona que de hecho consume, usa o utiliza los bienes o servicios".

${ }^{11}$ Barrientos Camus (2011) p. 363. En el mismo sentido Momberg Uribe (2004) pp. 41-62.

12 Véase Barrientos Camus (2011) p. 363 y (2016) p. 43, y Pinochet Olave (2011) pp. 360-361 quien distingue entre "consumidor jurídico" y "consumidor material" haciéndolo equivalente al de usuario, quien es el que utiliza o disfruta como destinario final el bien o servicio, y agrega que "[...] lo que propugnamos en este punto es una interpretación amplia del concepto de consumidor, de extraña por lo demás, en derecho comparado [...] incluyendo como puede observarse en la definición, las necesidades del grupo familiar, como aquellas que pueden legítimamente satisfacerse en el acto de consumo que ejecuta un miembro del grupo familia, sin por ello perder su naturaleza de acto de consumo"..

${ }^{13}$ Ha resultado problemático para la dogmática el concepto de consumidor. Se ha sostenido incluso que el concepto tradicional no proviene del Derecho. Para LETE ACHIRICA (1998) p. 184 "[...] el término consumidor, que viene empleándose con habitualidad en los sistemas jurídicos occidentales desde aproximadamente dos décadas, no es, sin embargo, un concepto originariamente jurídico sino socio económico. El Derecho lo ha tomado prestado para caracterizar las relaciones jurídicas merecedoras de cierta
} 
La jurisprudencia se mostró inicialmente reacia a la aceptación de la aplicación de la LPC al consumidor material ya que se entendía que la noción de consumidor sólo puede circunscribirse a aquel que efectivamente contrató con el proveedor (consumidor jurídico), por lo que algunas demandas no pudieron prosperar bajo ese argumento ${ }^{14}$.

En la actualidad el razonamiento que excluye al consumidor material del ámbito de aplicación de la LPC ya ha sido desplazado por uno que lo incluye por lo que hoy no se observan grandes problemas interpretativos para la protección de este tipo de consumidor cuyos derechos, como destinatario final del bien o servicio, también pueden verse vulnerados ${ }^{15}$.

BARRIENTOS CAMUS ha hecho un estudio acucioso de la contratación en el ámbito de consumo, especialmente sobre el incumplimiento contractual y las implicancias de que da cuenta el artículo 20 de la $\mathrm{LPC}^{16}$. Si bien de lege ferenda es necesario articular herramientas que permitan al consumidor material poder entablar acciones en contra del proveedor en caso de incumplimiento, v.g. garantía legal ${ }^{17}$, considero que es indispensable que esta categoría de consumidor posea dichas herramientas, no solamente para ejercer las prerrogativas que contempla el artículo 20, sino también para accionar ante cualquier afectación en sus derechos como consumidor. Dicho así, y en el evento que este tipo de

protección como consecuencia de la diversa posición que los empresarios y particulares ocupan en el mercado".

${ }^{14}$ En caso fundado en el daño que provocó la inundación de aguas servidas afectando a todos quienes habitan un inmueble, demanda interpuesta por los actores por sí y en representación de sus hijos menores, la Corte de Apelaciones de La Serena, Cofré y otros con Aguas del Valle, 29 de agosto de 2008, Rol 90-2008, entiende que los hijos no tienen la calidad de consumidores a la luz de la LPC: "[...] los menores, en la especie, no pueden ser sujetos activos respecto de la acción intentada"; Corte de Apelaciones de Chillán, No se consigna con no se consigna, 31 de julio de 2006, Rol 175-2006, considerando $3^{\circ}$ : “[...], en lo que respecta a la noción de consumidor, el legislador sigue asumiendo un concepto restringido porque, en primer lugar, se privilegia al sujeto consumidor por sobre lo que constituye el acto de consumo en sí mismo, asimilando el concepto de consumidor al de parte en el contrato de consumo. Así las cosas, no debe confundirse al consumidor jurídico parte del contrato de consumo con la de consumidor material del bien o servicio. Este último se encuentra privado de toda protección en el ámbito de la Ley 19.496".

${ }^{15}$ Así se ha resuelto, por ejemplo, por la Corte de Apelaciones de Concepción, Mendoza con S.A.C.I. Falabella, 28 de diciembre de 2012, Rol 203-2012, considerando $4^{\circ}:$ " [...], en nuestro derecho, el concepto de consumidor es bastante amplio, considera a todas las personas, a condición de que, cualquier de ellos, actué como destinatario final del bien o servicio objeto del contrato [...]", Corte de Apelaciones de Antofagasta, Leiva y otros con Sociedad Farmacias Ahumada S.A., 14 de noviembre de 2006, Rol 93-2006, considerando $5^{\circ}$ : "[...] puesto que los antecedentes allegados al proceso y estimados de conformidad con las reglas de la sana crítica, permiten establecer la relación de causalidad existente entre la contravención acreditada y el daño moral sufrido por el menor y sus padres, toda vez que el primero debió ser sometido a diversos tratamientos y sufrir las secuelas consecuentes por la ingesta de un medicamento equivocado, debiendo entenderse que el menor tantas veces citado es el verdadero "consumidor" a que se refiere la Ley 19.496 en su artículo $1^{\circ}(. .$.$) ",$ Corte de Apelaciones de Concepción, No se consigna con no se consigna, 17 de mayo de 2007, Rol 31-2007, especialmente considerando $2^{\circ}$, Corte de Apelaciones de Concepción, Sepúlveda y otros con Fuchs y Compañía Limitada, 8 de noviembre de 2007, Rol 500-2005, considerando $7^{\circ}$ : "El acto jurídico que menciona el artículo $1 \mathrm{~N}^{\mathrm{o}} 1$ de la Ley 19.496, es el factor de atribución que permite imputar a un proveedor determinado los efectos de este cuerpo legal; pero los afectados por esta relación de consumo pueden ser otros sujetos que no intervinieron en el acto jurídico, como en el caso de autos, toda la familia [...] que consumió la pasta de pollo y de huevo que ocasionó la intoxicación alimentaria".

${ }^{16}$ Véase BARRIENTOS CAMUS (2016).

${ }^{17}$ Barrientos CAMus (2016) p. 46 
consumidor haya sufrido un daño reparable por haber utilizado como destinatario final un bien o servicio, entonces corresponde reconocerle el derecho a ser indemnizado de todos los daños materiales y morales (art. 3 letra e) que se deriven de la infracción a la LPC, no siendo necesario, por tanto, que deba accionar en virtud del régimen general de responsabilidad del derecho común, sino más bien al amparo de esta especial norma protectora $^{18}$.

\subsection{Reformulación del concepto de proveedor}

La noción de proveedor también ha resultado problemática para la doctrina y jurisprudencia. No obstante, no se pretende, en este apartado, realizar un análisis completo de los tipos de proveedores que pueden existir, sino más bien señalar algunas ideas que se refieren a un concepto general y que tiene en cuenta el elemento central de la función de su función en una economía como la chilena.

Lo que cabe explicar, someramente, es el verdadero dilema jurídico y social al que está sometido el consumidor cuando es enfrentado al proveedor. Ciertamente aquí cabe distinguir el tipo de proveedor: pequeñas, medianas y grandes empresas (generalmente grupos económicos). Esto porque la capacidad económica y organizacional suele ser sustancialmente mayor en este último caso y, por consiguiente, el comportamiento exigible parece ser más estricto en proporción a su intervención y participación en el mercado.

Hay que reconocer que existen algunos proveedores que juegan un rol fundamental en la producción de bienes y servicios dentro de la comunidad, y lo hacen, naturalmente, dentro de un marco legal que permite el libre emprendimiento y/o libertad económica. Sin embargo, ello no debe llevar a una posición de poder sobre los consumidores en orden a cometer abusos, sino a la efectiva realización de la actividad mercantil en armonía con los derechos y pretensiones de estos. En efecto, si bien no se trata de hacer que las grandes empresas jueguen un rol solidario y de beneficencia para con el consumidor - por cuanto su esencia descansa precisamente en el lucro (que es totalmente legítimo) - su estructura, funcionamiento y repercusión en la vida cotidiana de todos los que adquieren sus productos o servicios se ve altamente afectada si no toman los resguardos necesarios para su correcto desarrollo y funcionamiento.

En ese orden de ideas, la empresa es, ciertamente, un ente necesario dentro de la comunidad para el progreso y desarrollo económico, pero ella carga implícitamente con el deber de sujetarse a la institucionalidad establecida, el bien común y el respeto de los derechos individuales y fundamentales de las personas. De hecho, es la misma Constitución la que impone ciertos límites a esta actividad en el artículo $19 \mathrm{n}^{\mathbf{0}} 21^{19}$.

\footnotetext{
${ }^{18}$ Incluso podría llegar a hablarse de consumidor en un sentido abstracto, esto es que ciudadano es equivalente a consumidor y por ende queda protegido por la LPC para entablar las acciones tendientes a la protección de sus derechos. Esta categoría ya ha sido identificada por ISLER SOTO (2013) p. 40.

${ }^{19} \mathrm{La}$ dogmática constitucional ha intentado definir algunos conceptos que se comprenden dentro de la lógica del emprendimiento económico. Por ejemplo, el "orden público económico" resulta ser un concepto complejo que, en algún sentido, implica la regulación de la actividad económica y un límite a la actividad empresarial. Véase CEA EgAÑA (1991) p. 18 (sobre el punto señala que "El Orden aludido puede ser conceptualizado como el conjunto de principios y normas jurídicas que organizan la economía del país y facultan a la autoridad para regularla en armonía con los valores de la sociedad nacional formulados en la Constitución").
} 
Una perspectiva reflexiva sobre el concepto y función del proveedor de bienes y servicios en una comunidad debe estar sometido necesariamente al escrutinio público. Es público en el sentido de que la actividad mercantil afecta transversalmente muchas áreas o fases a lo largo del proceso de producción llegando finalmente al consumidor. Así, el emprendimiento comienza con una iniciativa principalmente privada, cuyo objeto es generar ganancias. Pero para ello debe pasar por una serie de segmentos que necesariamente se ven enfrentadas con el interés personal del empresario. En primer término, el Estado dentro de su rol de fiscalizador; las autoridades administrativas; los trabajadores; los otros fabricantes, distribuidores o comerciantes; los consumidores y sociedad civil. Por esta razón, la actividad empresarial no es eminentemente privada, sino que necesariamente afecta intereses transversalmente públicos, debiendo estos ser considerados para que dicha actividad se encuentre en plena armonía con ellos.

La legislación de consumo funciona entonces como un mecanismo que puede ayudar a paliar y corregir algunos defectos del mercado y la actividad comercial ${ }^{20}$, de modo que sus normas no pueden ir en una dirección opuesta a los derechos del consumidor ni afectar su esencia $^{21}$. Por el contrario, debe haber una correcta armonía entre el interés privado y el público.

\subsection{Una nueva noción de relación de consumo. Factores que inciden en una aplicación extensiva de la $\mathrm{LPC}$}

Decir que la relación de consumo puede ser entendida en sentido amplio implica suponer que no solamente proviene de un contrato o de un acto jurídico oneroso sino que tiene una estructura compleja de la cual dependen los derechos e intereses involucrados ${ }^{22}$ y por ello cabe preguntarse sobre cómo nace o se articula esta relación.

Para abordar la respuesta a la interrogante es necesario primeramente descomponer las nociones que establece el artículo $1^{\circ}$ de la LPC y en razón de ellas intentar reestructurar la relación de consumo desde un enfoque crítico de manera que, si la tónica ha sido que el legislador pone el énfasis en ciertos elementos de esta relación para erigir su regulación y señalar el ámbito de aplicación, lo propio, entonces, es advertir sus elementos esenciales.

La LPC dispone en el artículo $1^{\circ}$ que "La presente ley tiene por objeto normar las relaciones entre proveedores y consumidores, establecer las infracciones en perjuicio del consumidor y señalar el procedimiento aplicable en estas materias" y que son consumidores o usuarios "las personas naturales o jurídicas, que, en virtud de cualquier acto jurídico oneroso, adquieren, utilizan, o disfrutan, como destinatarios finales, bienes o servicios. En ningún caso podrán ser considerados consumidores los que de acuerdo al

\footnotetext{
${ }^{20}$ En este sentido, por todos, ALVEAR TÉLLEZ (2017) p. 182

${ }^{21}$ Con la actual regulación de la LPC por su confusa técnica de redacción y por la aun no resuelta configuración completa de los derechos del consumidor frente a los del empresario, todavía existe una tensión normativa permanente.

${ }^{22}$ FuENZALIDA ROBLEDO (2018) pp. 129-131 afirma que la responsabilidad civil que se regula en la LPC trasciende el contrato de consumo, no siendo este indispensable para que tenga lugar sino que es suficiente el hecho mismo del consumo, en tanto adquirir, usar o disfrutar.
} 
número siguiente deban entenderse como proveedores" y éstos son, conforme al número 2 del artículo precitado, "las personas naturales o jurídicas, de carácter público o privado, que habitualmente desarrollen actividades de producción, fabricación, importación, construcción, distribución o comercialización de bienes o de prestación de servicios a consumidores, por las que se cobre precio o tarifa".

Como queda en evidencia, la LPC tiene un texto restringido, en cuanto a que la relación de consumo solo puede tener origen en actos jurídicos onerosos, celebrados por un proveedor y un consumidor, para la adquisición de bienes o servicios por los cuales se ha cobrado precio o tarifa. Si esto es plenamente correcto entonces todas las hipótesis en que no se den los presupuestos que el artículo $1^{\circ}$ señala devienen en la no existencia de relación de consumo y por consiguiente no sería aplicable esta especial legislación al caso concreto.

Un análisis dogmático de la noción de relación de consumo junto con una mirada a la práctica judicial pueden ofrecer una interpretación más favorable al consumidor, especialmente a través de algunos factores que inciden directamente en una aplicación extensiva de la LPC dando cabida a una noción amplia de relación de consumo porque prescinde del supuesto contemplado en el artículo $1^{\circ}$ de la onerosidad del acto.

\section{A) GRATUIDAD DEL ACTO}

De esta forma, y considerando críticamente la actual estructuración de la relación de consumo, puede notarse un avance en la jurisprudencia sobre los factores o componentes que inciden en ella, llegando a conclusiones más amplias e incluso -en ocasiones- contra la literalidad del texto normativo.

Sobre lo último hay que decir que la relación de consumo no solamente se erige sobre una relación negocial cuya base sea la existencia de un acto jurídico oneroso, o bien que deba cobrarse precio o tarifa o que el consumidor sea el mismo que contrató con el proveedor, etc., sino que esta se crea y articula de un modo mucho más complejo e interconectado con una serie de actos que no necesariamente son onerosos. Entender así la relación entre proveedor y consumidor permite aplicar el régimen especial a diversas situaciones.

Por lo tanto, esta segunda forma de estructurar la relación de consumo (en el sentido amplio) puede ser comprendida desde dos enfoques: a) El consumidor no alcanza a celebrar un acto jurídico oneroso, b) El consumidor realiza un acto de consumo gratuito.

\section{a) El consumidor no alcanza a celebrar un acto jurídico oneroso}

Este caso llama la atención porque el consumidor no celebrando el acto de consumo típico (concurriendo los elementos del art. $1^{\circ}$ LPC) igualmente puede quedar protegido o amparado por la norma, y tal acontece con el extraño que situado en un espacio físico del proveedor sufre algún daño a raíz del cual resulta aplicable la legislación de consumo.

Un fallo de la Corte de Apelaciones de San Miguel, de 21 de octubre de 2009, concluye, en su considerando sexto, lo que se está diciendo: “... no tan solo la venta constituye el acto que protege la ley 19.496, sino, tal como se señalara precedentemente, lo forman también 
todos los actos que permiten que ella se efectúe, no siendo indispensable que efectivamente se compre un bien..." 23 (énfasis añadido).

La conclusión obvia de la sentencia es que no se requiere que exista un acto jurídico oneroso que vincule al proveedor con el consumidor sino que basta que este se haya dispuesto a celebrarlo aunque no logre concretarlo.

Así, si se sustrae un vehículo o una especie desde los estacionamientos del proveedor basta que el consumidor lo haya dejado en las dependencias del centro comercial $^{24}$ con la finalidad de adquirir bienes o servicios para que la LPC resulte totalmente procedente y aplicable, solo que la protección se da siempre en el marco del deber diligencia y seguridad que pesa sobre el proveedor y el correlativo derecho del consumidor de acuerdo al artículo $3^{\circ}$ letra d) siendo indiferente si se compró o no efectivamente un bien. Lo mismo pasa si una persona ingresa a un centro comercial y, antes de haber concretado una compra, sufre un accidente debido a la omisión de deberes de diligencia del proveedor, tales como resguardar que en los pasillos no haya sustancias que puedan provocar la caída de quienes por ahí transitan ${ }^{25}$.

Acontecimientos como los descritos no debiesen parecer extraños pues la misma LPC regula algunos en los que no se requiere la celebración de acto jurídico oneroso y pese a ello existe protección jurídica a favor del consumidor cual sucede con, por ejemplo, la regulación de los sistemas de seguridad y vigilancia en los establecimientos comerciales (art. 15), la publicidad engañosa (art. 28), los defectos en la información precontractual o información básica comercial (art. $1^{\circ} \mathrm{N}^{\mathrm{o}} 3$ ), la seguridad de los productos (art. 44 y ss.).

De este modo, el ámbito de protección de los derechos del consumidor no opera solamente en un plano contractual, o bajo la vinculación de un acto jurídico oneroso, entre un proveedor determinado y un consumidor determinado, sino que la relación más bien se determina por una secuencia de actos que permiten presumir que una persona, aunque no haya comprado un bien, ha ejecutado actos tendientes a la compra o a la prestación del servicio que se dispuso adquirir.

Varios fallos admiten que la calidad de consumidor no requiere la efectiva contratación, compra o adquisición de un bien o servicio, una sentencia de la Corte de Apelaciones de La Serena de 11 de diciembre de 2008 establece que

"[...], la citada ley, como se ha señalado, entrega una normativa completa sobre las relaciones de consumo, sin que para su aplicación resulte esencial la existencia de un vínculo jurídico previo, esto es, que se haya concretado la compraventa con el pago de los productos seleccionados por el querellante [...].

\footnotetext{
${ }^{23}$ Véase Corte de Apelaciones de San Miguel, Sernac contra Sociedad Plaza Tobalaba S.A., 21 de octubre de 2009, Rol 646-2009, especialmente considerando 6º . En el mismo sentido AEdo BARRENA (2010) p. 225.

${ }^{24}$ Véase Corte de Apelaciones de Santiago, No se consigna con Administradora Plaza Vespucio S.A., 13 de abril de 2012, Rol 1773-2011, Corte de Apelaciones de Chillán, Matus de la Parra con Restaurant L Acogida, 18 de noviembre de 2013, Rol 86-2013.

${ }^{25}$ Corte de Apelaciones de Iquique, Parada con Cencosud Supermercado S.A., 29 de julio de 2011, Rol 252011, Corte de Apelaciones de La Serena, Cabello con Supermercado Santa Isabel, 7 de febrero de 2007, Rol 278-2006.
} 
Cabe advertir que la citada ley emplea el término consumidor en situaciones que no tienen como supuesto la existencia de un contrato, como, por ejemplo, sus artículos 13 y 15, los cuales imponen obligaciones al proveedor respecto del consumidor no contratante. En igual sentido se encuentra el artículo 12, que está bajo el título de las Obligaciones del proveedor que exige a todo proveedor de bienes o servicios respetar los términos, condiciones y modalidades conforme a las cuales se hubiera ofrecido o convenido con el consumidor la entrega del bien o la prestación del servicio (...). Como corolario de todo lo relacionado se puede concluir, como ya se ha adelantado, que en rigor, la calidad de consumidor no sólo la tiene quien ha comprado el bien, sino que también la persona que con tal propósito se encuentra al interior del local, como ha acontecido en la especie [...]",26.

\section{b) El consumidor realiza un acto de consumo gratuito}

Este supuesto se refiere a que el consumidor se relaciona con el proveedor mediante un acto jurídico gratuito principal o un acto gratuito accesorio a uno principal oneroso.

Los ejemplos más comunes y repetidos en la práctica judicial se refieren a daños que ocurren en los estacionamientos de un centro comercial (robo de vehículo o de especies en su interior), cuyo ingreso es gratuito para el cliente con la finalidad de facilitar tanto el acceso y el transporte de los productos que adquiera ${ }^{27}$.

${ }^{26}$ Corte de Apelaciones de La Serena, Araya con Cencosud Supermercados S.A., 11 de diciembre de 2008, Rol 181-2008, especialmente considerando $3^{\circ}$. En la misma línea Corte de Apelaciones de Concepción, Sierra con Johnsons S.A., 10 de septiembre de 2010, Rol 286-2010, considerando $3^{\circ}$, Corte de Apelaciones de Valparaiso, Becerra contra Fallabella S.A., 11 de abril de 2008, Rol 98-2008, considerando $7^{\circ}$ : "[...], si bien es cierto, en el inciso 1 de la disposición citada, se señala qué debe entenderse por consumidores o usuarios, no parece legítimo aceptar [...] que estime excluidos de dicha definición aquellas personas que no obstante su intención de adquirir algún bien ofrecido por el proveedor finalmente, por cualquier motivo, como en la especie, no lo adquiere.”. Véase Corte de Apelaciones de La Serena, Céspedes con Homecenter Real y otros, 25 de julio de 2008, Rol 36-2008, especialmente considerando 6º ${ }^{\circ}$ Corte de Apelaciones de La Serena, Olivares con Tienda Mega Jonhsons S.A., 28 de noviembre de 2008, Rol 176-2008, considerando 5: "Por tanto, la calidad de consumidor para los efectos de la ley aludida no sólo la ostenta quien ha comprado un bien, sino también, la persona que se encuentre en el interior de la tienda en calidad de cliente, no obstante no haber adquirido aun especie alguna, única interpretación que permite entender la utilización del término consumidor [...]" (énfasis añadido), Corte de Apelaciones de Iquique, Parada con Cencosud Supermercados S.A., 29 de julio de 2011, Rol 25-2011, especialmente considerando $5^{\circ}$, Corte de Apelaciones de Coyhaique, Ortiz con ABC DIN S.A., 10 de septiembre de 2015, Rol 14-2015, especialmente considerando $4^{\circ}$, Corte de Apelaciones de Concepción, No se consigna con no se consigna, 16 de marzo de 2016, Rol 6342015, especialmente considerando $7^{\circ}$.

${ }^{27}$ Por ejemplo, en recurso de queja interpuesto por Cencosud S.A, la Corte Suprema examina la aplicación de la LPC a daños producidos en estacionamientos que se proveen de forma gratuita al cliente y señala que, especialmente en el considerando $5^{\circ}$, "Pero no se trata de la sola exigencia de la autoridad encargada de la construcción y el urbanismo público, ni de la comodidad del cliente, sino de la obligación, impuesta por la ley, de poner la cosa en disposición de entregarla, lo que supone facilitar la salida desde el interior del local a un lugar donde la persona pueda subirla a su medio de transporte, asumiendo el cliente el costo de su traslado. Esa facilidad de disposición, hoy en día constituye el estacionamiento y dado que los costos de aquella son del vendedor, a él corresponde velar porque el lugar que ha facilitado a los consumidores para que instalen sus vehículos sea tan seguro, como debe serlo el paquete de pan o la caja de leche que les vende. Tanto es así, que como puede advertirse, incluso en la mayoría de los establecimientos de este tipo, se reserva 
Sobre esto la jurisprudencia está dividida, existiendo fallos que acogen la acción indemnizatoria interpuesta por el consumidor, sustentándose en que la relación de consumo se desarrolla sobre una serie de actos sucesivos que comienzan con el ingreso del cliente a los estacionamientos o en que el hecho de usar gratuitamente el estacionamiento no es una actividad aislada sino que forma parte de los términos y condiciones del servicio que se presta de conformidad al artículo 12 de la LPC de modo que, aunque no se cobre precio o tarifa por este servicio, igualmente el consumidor quedara protegido ${ }^{28}$.

Por su parte, otros tribunales se pronuncian en un sentido totalmente contrario, es decir, la existencia de un acto gratuito (como el de los estacionamientos que revisten ese carácter) no pueden ser considerados parte integrante de la relación principal onerosa de consumo, por lo que la víctima no puede demandar los perjuicios sufridos en base a esta especial regulación ${ }^{29}$.

Ahora bien, en la actualidad tanto la dogmática como la jurisprudencia se han mostrado favorables a una interpretación más bien extensiva de la LPC. Hay una serie de fallos que derechamente incluyen la gratuidad como otro ámbito de aplicación importante, por lo que no se requiere realizar una argumentación tan extenuante para que la acción infraccional y civil sean acogidas ${ }^{30}$.

un lugar para los taxis que han sido autorizados por el supermercado para ubicarse permanentemente en él y ofrecer su servicio a los clientes que no concurren en vehículo propio y que sacan sus compras hasta el estacionamiento en los mismos carros que el supermercado les facilita" (énfasis agregado). Véase Corte Suprema, Cencosud Supermercados S.A. con No se consigna, 16 de mayo de 2011, Rol 3299-2010, Corte de Apelaciones de Concepción, No se consigna con no se consigna, 28 de septiembre de 2015, Rol 575-2015, especialmente considerando $6^{\circ}$.

${ }^{28}$ Véase Corte de Apelaciones de Antofagasta, Cortez con Hotel Terrado Suites Antofagasta, 9 de septiembre de 2016, Rol 72-2016, Corte de Apelaciones de Santiago, Muñoz con Cencosud Retail S.A., 8 de julio de 2016, Rol 650-2016, Corte de Apelaciones de Chillán, Matus de la Parra con Restaurant L Acogida, 18 de noviembre de 2013, Rol 86-2013. En la doctrina se ha planteado en un mismo sentido, especialmente TAPIA Rodríguez y VAldivia Olivares (2002) p. 57, Isler Soto (2010) p. 107. Puede verse también De LA MAZA GAZMURi y OJEDA MONTOYA (2016) pp. 70 y ss.

${ }^{29}$ Véase Corte de Apelaciones de Santiago, Rainao con Arcos Dorados Restaurantes de Chile Limitada, 3 de agosto de 2016, Rol 748-2016, Corte de Apelaciones de Santiago, Lizama con Lider Domicilio Ventas y Distribución Limitada, 7 de noviembre de 2016, Rol 1273-2016; en cierto modo también Corte de Apelaciones de Santiago, Sánchez con Administradora de Supermercados Hiper Limitada, 16 de diciembre de 2016, Rol 1606-2016.

${ }^{30}$ Por ejemplo, Corte de Apelaciones de San Miguel, Cereño con Plaza Tobalaba S.A., 22 de septiembre de 2011, Rol 656-2011, especialmente considerando 3º, Corte de Apelaciones de Antofagasta, Leaño con Hipermercado Antofagasta Limitada, 20 de julio de 2012, Rol 100-2012, especialmente considerando $6^{\circ}$, Corte de Apelaciones de Puerto Montt, Valenzuela con Cencosud Retail S.A., 19 de julio de 2013, Rol 682013, especialmente considerando 5 , Corte de Apelaciones de Antofagasta, Palacios con Plaza Antofagasta S.A., 22 de agosto de 2013, Rol 61-2013, especialmente considerando 8º Corte de Apelaciones de Santiago: Peña con Cencosud Retail S.A., 20 de agosto de 2013, Rol 165-2012, especialmente considerando $5^{\circ}$, Sernac con Supermercado Independencia Limitada, 13 de diciembre de 2013, Rol 1818-2012, especialmente considerando 6 $6^{\circ}$, Sernac con Plaza Vespucio S.A., 17 de abril de 2014, Rol 1915-2013, especialmente considerando 31 ${ }^{\circ}$, Sernac con Easy S.A., 15 de mayo de 2014, Rol 2120-2013, especialmente considerando $4^{\circ}$, Sernac y Valdebenito con Cencosud Retail S.A., 9 de junio de 2014, Rol 2083-2013, especialmente considerando $1^{\circ}$, Corte de Apelaciones de Antofagasta, Jara con Rendir Hermanos S.A. y otro, 9 de mayo de 2014, Rol 138-2013, especialmente considerando 6 ${ }^{\circ}$, Corte de Apelaciones de Chillán, Escobar con Cencosud Retail S.A., 16 de junio de 2014, Rol 35-2014, especialmente considerando $3^{\circ}$. 
Esta interpretación es la que cada vez tiene mayor fuerza, porque ofrece una protección mucho más robusta al consumidor, además de establecer criterios para una adecuada tutela de sus derechos e intereses.

\section{B) CIRCUNSTANCIAS REGULADAS SIN VÍNCULO CONTRACTUAL}

Otra razón por la que se puede concluir que la LPC tiene una aplicación extensiva, en cuanto supera la mera relación generada por un acto jurídico oneroso, es que existen variadas disposiciones dentro de la misma que regulan situaciones en que no hay vínculo contractual y pese a ello se respetan las categorías de proveedor y consumidor desde una perspectiva abstracta posibilitando el resguardo de los derechos y deberes de ambas partes.

A continuación, se exponen sucintamente algunas razones específicas.

\section{a) Protección de la dignidad de los consumidores}

El artículo 15 de la LPC señala "Los sistemas de seguridad y vigilancia que, en conformidad a las leyes que los regulan, mantengan los establecimientos comerciales están especialmente obligados a respetar la dignidad y derechos de las personas" y el inciso segundo que "En caso que se sorprenda a un consumidor en la comisión flagrante de un delito [...]”.

Una lectura razonada del texto normativo debería llevar a la conclusión de que es la misma ley la que identifica un concepto amplísimo de consumidor, casi equivalente a la de ciudadano $^{31}$ de modo que no puede verse limitada a la noción tipificada en el artículo $1^{\circ}$ porque por no contratar no se pierde la calidad de consumidor $\mathrm{y}$, al contrario, la normativa impone al proveedor resguardar la dignidad de las personas tratándose de las medidas de seguridad adoptadas por un establecimiento comercial por lo que su obligación se refiere a un sujeto indeterminado que poco a poco puede tomar cierta determinación y la tendrá, desde luego, cuando se vincule directamente con el proveedor ${ }^{32}$.

\section{b) Información comercial}

En el artículo $1^{\circ}$ número 3 de la LPC se establecen las normas básicas de información comercial con el siguiente tenor: "Información básica comercial: los datos, instructivos, antecedentes o indicaciones que el proveedor debe suministrar obligatoriamente al público consumidor, en cumplimiento de una norma jurídica" (énfasis añadido). Luego el inciso 4 del mismo número señala que "La información comercial básica deberá ser suministrada al público por medios que aseguren un acceso claro, expedito y oportuno. Respecto de los instructivos de uso de los bienes y servicios cuyo uso normal represente un riesgo para la seguridad e integridad de las personas, será obligatoria su entrega al consumidor conjuntamente con los bienes y servicios a que acceden" (énfasis añadido).

\footnotetext{
${ }^{31}$ Este tipo de definiciones ya ha sido señalado por alguna doctrina, especialmente BERCOVITZ RODRÍGUEZCANO (1987) p. 17 quien identifica un concepto amplio de consumidor como consumidor-ciudadadano.

${ }^{32}$ En este sentido TAPIA RodRÍGUEZ (2017) p. 51.
} 
Los términos utilizados por la misma LPC, en cuanto a la información básica comercial, no suponen que el consumidor haya celebrado un acto jurídico oneroso o que se halle en la posibilidad de hacerlo cuando se encuentre en las dependencias del establecimiento del proveedor, sino que más bien constituyen obligaciones o deberes generales respecto de la masa de personas que actual o potencialmente adquieran los bienes y/o servicios de los proveedores. Esto permite concluir que es la misma ley la que acepta una aplicación extensiva de ella, mucho más cuando utiliza los términos "público consumidor", "público" o "personas", de modo que no es requisito la celebración de un acto jurídico oneroso para ser considerado consumidor. Más bien, diríamos, se trata de un concepto que se confunde con una noción abstracta de consumidor, en tanto persona.

\section{c) Publicidad}

Con la publicidad se llega a igual conclusión que en el apartado anterior porque es el mismo precepto contenido en el número 4 del artículo $1^{\circ}$ de la LPC el que se pronuncia sobre ella en términos similares a la información comercial pues se establece: "Publicidad: la comunicación que el proveedor dirige al público por cualquier medio idóneo al efecto, para informarlo y motivarlo a adquirir o contratar un bien o servicio [...]" (énfasis añadido).

El concepto de consumidor se confunde con el de "público" por lo que también existe una noción amplia que permite una aplicación extensiva de la ley.

\section{d) Acciones de interés difuso}

Finalmente, una razón que sirve para fundar la aplicación extensiva de la ley es la articulación de acciones de interés difuso que se concede a un conjunto indeterminado de consumidores afectados en sus derechos (ahora art. 50 inciso $5^{\circ}$ de la LPC, modificado por la Ley 21.081). En este caso no se requiere la existencia de vínculo contractual con el proveedor (como si lo exigen las acciones de interés colectivo) lo que permite concluir que la LPC protege incluso aquellas personas que no han celebrado acto jurídico oneroso ${ }^{33}$.

\section{HACIA LA NOCIÓN DE RELACIÓN DE CONSUMO}

Como ya ha quedado de manifiesto, desde un punto de vista legal la relación de consumo suele articularse mayoritariamente en virtud de un contrato o de un acto jurídico oneroso (art. $1^{\circ}$ LPC) pero dicha acepción ha sido superada por la dogmática y la jurisprudencia porque la relación entre proveedor y consumidor trasciende la mera interacción onerosa y

\footnotetext{
${ }^{33}$ Mismo sentido, TAPIA RodríGUEZ (2017) pp. 50-51, con quien coincido plenamente. El autor señala que el reconocimiento de las acciones de interés difuso es "[...] un argumento contundente que permite extender la protección sin requerir la prueba de un acto jurídico. En efecto, ¿qué sentido habría tenido introducir estas acciones por interés difuso si se concluye que, tal como las acciones por interés colectivo, exigen la comprobación de un acto jurídico entre el proveedor y el consumidor afectado? En mi opinión, ello no tendría sentido alguno, y debe concluirse, en consecuencia, que esta reforma es una prueba inequívoca de que aun en ausencia de actos jurídicos puede aplicarse la LPC".
} 
convencional, expandiendo, por consiguiente, su ámbito de aplicación aún en ausencia de vinculación contractual directa.

Adicionalmente, se entiende que también hay relación de consumo cuando el acto es gratuito o no se alcanza a celebrar ninguno por diversas razones.

En la doctrina también se ha desarrollado un concepto de relación de consumo indicándose que consiste en el "vínculo jurídico de fuente legal que liga al proveedor de bienes o servicios con el consumidor que los adquiere o utiliza como destinatario final, así como con todos aquellos que se ven afectados por sus consecuencias o, en general, por la actividad de los proveedores" ${ }^{34}$. Esta definición ciertamente comprende muchas más hipótesis de aplicación comparada con la de acto jurídico oneroso de la LPC, probablemente no utiliza la vinculación contractual dentro de su definición pero debe subsumirse en ella. Esto refleja que la relación de consumo es una noción extraordinariamente amplia y compleja, entregando a los tribunales la posibilidad de determinar a quiénes se puede extender esa relación para ser titular de los derechos que consagra la legislación de consumo. En principio, todo indicaría que esas personas deben haber disfrutado del bien o servicio, al margen de su vinculación con el proveedor, o al menos haber sido afectadas por este con ocasión de su actividad comercial, sin necesidad de algún acuerdo o contrato previo.

\section{CONCLUSIONES}

1. La redacción de la LPC ofrece una visión tremendamente restringida de la noción de relación de consumo fundada en el acto jurídico oneroso.

2. Ha tenido que ser la doctrina pero especialmente la jurisprudencia la que se ha hecho cargo en gran medida de los aspectos deficitarios tanto a la conceptuación y aplicación de la ley a casos particulares, sobre todo por su tono restringido. Hoy, la gratuidad del acto permite configurar de igual modo una relación de consumo excluyendo la exigencia del acto oneroso.

3. Hay un constante progreso y evolución de la forma en cómo se va entendiendo la relación de consumo en Chile y la noción que se tiene de los actores más importantes: consumidor y proveedor. Obviamente es necesaria una reforma legislativa para que los tribunales no tengan que extender la norma a sectores recónditos para dar soluciones a problemas complejos, pero para ello se requiere una compresión completa de lo que significa ser consumidor en sociedad donde el mercado ha llegado casi todos los ámbitos de la vida de las personas, como también del rol que efectivamente le corresponde al proveedor en una economía como la nuestra. Sin estas consideraciones la labor de la dogmática y la jurisprudencia serán tan arduas como lo han sido hasta ahora, intentando dar armonía a los derechos de las dos partes involucradas que, para algunos (quizá la mayoría), presenta una permanente tensión y enfrentamiento antagónico.

\footnotetext{
${ }^{34}$ ZENTNER (2010) p. 68.
} 
4. La distinción entre consumidor jurídico y material resulta tremendamente útil para resolver contiendas en la práctica judicial. La introducción de esta nueva categoría ayuda a comprender el real sentido que puede tener la LPC para proteger a quienes incluso no han celebrado ningún acto con el proveedor, pero cuyos derechos resultan perjudicados por su actividad. De esto se concluye que la noción de consumidor no es unívoco y que por tanto dependerá de las particulares circunstancias sobre las que se desarrollen los hechos.

5. La relación de consumo consiste en una vinculación normativa entre el proveedor y consumidor, ya sea que esta tenga su origen en la ley o en acto jurídico oneroso o gratuito; o, sin haberlo celebrado, por el hecho de haber adquirido, usado, utilizado o disfrutado de un bien o servicio que el primero entregue al segundo en el mercado o hayan llegado a este por otras formas legítimas, hecho a partir del cual dicho consumidor adquiere esta misma calidad, que sirve de base para ser titular de las prerrogativas, derechos y deberes reconocidos por la legislación de consumo.

\section{BIBLIOGRAFÍA CITADA}

Aedo Barrena, Cristian (2010) "El uso de estacionamientos como acto de consumo: reflexiones sobre la causalidad y la culpa", Revista de Derecho Universidad Católica del Norte, vol. 17, $\mathrm{N}^{\mathrm{o}}$ 1, pp. 213-239. Disponible en: http://revistaderecho.ucn.cl/article/view/2069/1695, fecha de consulta: 5 de agosto de 2018.

AlveAR TÉLleZ, Julio (2017) Libertad económica, libre competencia y derecho del consumidor. Un panorama crítico. Una visión integral (Valencia, Editorial Tirant Lo Blanch).

BARRIENTOS CAMus, Francisca (2011): "Derecho del consumo", Revista Chilena de Derecho Privado, № 16, pp. 359-366. Disponible en: https://scielo.conicyt.cl/pdf/rchdp/n16/art12.pdf, fecha de consulta: 5 de julio de 2018.

, (2012): “Por qué no hay demandas de responsabilidad civil contra el fabricante?”, en BARRIEntos CAMus, Francisca et al., Consumidores (Santiago de Chile, AbeledoPerrot Thomson Reuters), pp. 377-399.

, (2016): La Garantía Legal (Santiago de Chile, Thomson Reuters).

BERCOVITZ RodríGueZ-CANO, Alberto (1987): “Ámbito de aplicación y derechos de los consumidores en la Ley General para la Defensa de los Consumidores y Usuarios, en Estudios Jurídicos sobre la protección de los consumidores (Madrid, Tecnos).

Cea Egaña, José Luis (1991) "Notas sobre Orden Público Económico”, Gaceta Jurídica $\mathrm{N}^{\circ} 135$, pp. 18-32.

De la MaZa Gazmuri, Íñigo y Vidal Olivares, Álvaro (2014): "Propósito práctico, incumplimiento contractual y remedios del acreedor. Con ocasión de tres recientes 
sentencias de la Corte Suprema", Ius et Praxis, vol. 20, № 1, pp. 15-38. Disponible en: https://scielo.conicyt.cl/pdf/iusetp/v20n1/art02.pdf, fecha de consulta: 12 de julio de 2018.

De la MaZa GazMuri, Íñigo y OJEDA Montoya, Hugo: (2016): "El costo de la gratuidad: el caso de los estacionamientos", Revista de Derecho de la Universidad de Concepción, $\mathrm{N}^{\mathrm{o}}$ 239, año LXXXIV, pp. 59-101. Disponible en: http://www.revistadederecho.com/pdf.php?id=3189, fecha de consulta: 22 de julio de 2018.

FuENZALIDA RoBledo, Eduardo (2018): "El acto de consumo como hecho y la responsabilidad civil" en Revista de Derecho Universidad Católica del Norte, vol. 25, $\quad \mathrm{N}^{\mathrm{N}} \quad 1, \quad$ pp. 121-152. Disponible en: http://revistaderecho.ucn.cl/article/view/2999/2832, fecha de consulta: 28 de agosto de 2018.

ISLER SOTO, Erika (2010): "La relación de consumo como criterio de aplicabilidad del Derecho de protección del Consumidor", Revista de Derecho de la Empresa, № 23, pp. 97-126.

, (2013): El producto defectuoso en la ley 19.496 (Santiago de Chile, Editorial Librotecnia).

JARA Amigo, Rony (1999): “Ámbito de aplicación de la ley chilena de protección al consumidor: inclusiones y exclusiones”, en CORRAL TALCIANI, Hernán (Ed.), Derecho del Consumo y protección al consumidor (Santiago de Chile, Editorial Universidad de los Andes), pp. 47-74.

LETE ACHIRICA, Javier (1998) "La armonización de las legislaciones europeas sobre protección de los consumidores a la luz del derecho comunitario", Actualidad Civil, $\mathrm{N}^{\mathrm{o}} 1$, pp. 183-201.

LóPeZ SANTA MARÍA, Jorge (2010) Los contratos Parte General (5ª ed., Santiago de Chile, LegalPublishing).

Momberg UriBe, Rodrigo (2004): “Ámbito de aplicación de la Ley N 19.496 sobre Protección de los Derechos de los Consumidores", Revista de Derecho (Valdivia), vol. 17, $\mathrm{N}^{\circ}$ 2, pp. 41-62.

PinOCHET Olave, Ruperto (2011): "Delimitación material del Derecho de consumo: Evolución de la noción de consumidor en la doctrina nacional", Estudios de Derecho Comercial, pp. 343-367 (Santiago de Chile, LegalPublishing).

TAPIA RodrígueZ, Mauricio (2017) Protección de Consumidores. Revisión crítica de su ámbito de aplicación (Santiago de Chile, Rubicón Editores). 
TAPIA Rodríguez, Mauricio y VALdivia Olivares, José Miguel (2002): El contrato por adhesión: Ley $N^{o} 19.496$ (Santiago de Chile, Editorial Jurídica de Chile).

ZENTNER, Diego (2010): Contrato de consumo (Buenos Aires, La Ley).

\section{NORMAS CITADAS}

Ley 19.496 (7/3/1997) Establece Normas sobre protección de los derechos de los consumidores

Código Civil de la República de Chile

Constitución Política de la República de Chile

\section{JURISPRUDENCIA CITADA}

Corte de Apelaciones de Valparaíso, Garrido con Empresa Savilco Ltda. (2005): 29 de agosto de 2005, Rol 7693-2004, Thomson Reuters CL/JUR/3784/2005.

Corte de Apelaciones de Chillán, No se consigna con No se consigna (2006): 31 de julio de 2006, Rol 175-2006, Thomson Reuters CL/JUR/2438/2006.

Corte de Apelaciones de Antofagasta, Leiva y otros con Sociedad Farmacias Ahumada S.A. (2006): 14 de noviembre de 2006, Rol 93-2006, Thomson Reuters CL/JUR/3800/2006.

Corte de Apelaciones de La Serena, Cabello con Supermercado Santa Isabel (2007): 7 de febrero de 2007, Rol 278-2006, Thomson Reuters CL/JUR/321/2007.

Corte de Apelaciones de Concepción, No se consigna con No se consigna (2007): 17 de mayo de 2007, Rol 31-2007, Thomson Reuters CL/JUR/904/2007.

Corte de Apelaciones de Concepción, Sepúlveda y otros con Fuchs y Compañía Limitada (2007): 8 de noviembre de 2007, Rol 500-2005, Thomson Reuters CL/JUR/5582/2007.

Corte de Apelaciones de Valparaiso, Becerra contra Fallabella S.A. (2008): 11 de abril de 2008, Rol 98-2008, Thomson Reuters CL/JUR/926/2008.

Corte de Apelaciones de La Serena, Céspedes con Homecenter Real y otros (2008): 25 de julio de 2008, Rol 36-2008, Thomson Reuters CL/JUR/5422/2008.

Corte de Apelaciones de La Serena, Cofré y otros con Aguas del Valle (2008): 29 de agosto de 2008, Rol 90-2008, Thomson Reuters CL/JUR/3350/2008. 
Corte de Apelaciones de La Serena, Olivares con Tienda Mega Jonhsons S.A. (2008): 28 de noviembre de 2008, Rol 176-2008, Thomson Reuters CL/JUR/4202/2008.

Corte de Apelaciones de La Serena, Araya con Cencosud Supermercados S.A. (2008): 11 de diciembre de 2008, Rol 181-2008, Thomson Reuters CL/JUR/6019/2008.

Corte de Apelaciones de San Miguel, Sernac contra Sociedad Plaza Tobalaba S.A. (2009): 21 de octubre de 2009, Rol 646-2009, Thomson Reuters CL/JUR/2481/2009.

Corte de Apelaciones de Concepción, Sierra con Johnsons S.A. (2010): 10 de septiembre de 2010, Rol 286-2010, Thomson Reuters CL/JUR/7017/2010.

Corte Suprema, Cencosud Supermercados S.A. con No se consigna (2011): 16 de mayo de 2011, Rol 3299-2010, Thomson Reuters CL/JUR/4169/2011.

Corte de Apelaciones de Iquique, Parada con Cencosud Supermercados S.A. (2011): 29 de julio de 2011, Rol 25-2011, Thomson Reuters CL/JUR/6094/2011.

Corte de Apelaciones de San Miguel, Cereño con Plaza Tobalaba S.A. (2011): 22 de septiembre de 2011, Rol 656-2011, Thomson Reuters CL/JUR/7803/2011.

Corte de Apelaciones de Santiago, No se consigna con Administradora Plaza Vespucio S.A. (2012): 13 de abril de 2012, Rol 1773-2011, Thomson Reuters CL/JUR/921/2012.

Corte de Apelaciones de Antofagasta, Leaño con Hipermercado Antofagasta Limitada (2012): 20 de julio de 2012, Rol 100-2012, Thomson Reuters CL/JUR/4114/2012.

Corte de Apelaciones de Concepción, Mendoza con S.A.C.I. Falabella (2012): 28 de diciembre de 2012, Rol 203-2012, Thomson Reuters CL/JUR/2987/2012.

Corte de Apelaciones de Puerto Montt, Valenzuela con Cencosud Retail S.A. (2013): 19 de julio de 2013, Rol 68-2013, Thomson Reuters CL/JUR/1579/2013.

Corte de Apelaciones de Santiago, Peña con Cencosud Retail S.A. (2013): 20 de agosto de 2013, Rol 165-2012, Thomson Reuters CL/JUR/1944/2013.

Corte de Apelaciones de Antofagasta, Palacios con Plaza Antofagasta S.A. (2013): 22 de agosto de 2013, Rol 61-2013, Thomson Reuters CL/JUR/2337/2013.

Corte de Apelaciones de Chillán, Matus de la Parra con Restaurant L Acogida (2013): 18 de noviembre de 2013, Rol 86-2013, Thomson Reuters CL/JUR/2683/2013.

Corte de Apelaciones de Santiago, Sernac con Supermercado Independencia Limitada (2013): 13 de diciembre de 2013, Rol 1818-2012, Thomson Reuters CL/JUR/2916/2013. 
Corte de Apelaciones de Santiago, Sernac con Plaza Vespucio S.A. (2014): 17 de abril de 2014, Rol 1915-2013, Thomson Reuters CL/JUR/1430/2014.

Corte de Apelaciones de Antofagasta, Jara con Rendir Hermanos S.A. y otro (2014): 9 de mayo de 2014, Rol 138-2013, Thomson Reuters Cl/JUR/2335/2014.

Corte de Apelaciones de Santiago, Sernac con Easy S.A. (2014): 15 de mayo de 2014, Rol 2120-2013, Thomson Reuters CL/JUR/2461/2014.

Corte de Apelaciones de Santiago, Sernac y Valdebenito con Cencosud Retail S.A. (2014): 9 de junio de 2014, Rol 2083-2013, Thomson Reuters CL/JUR/3143/2014.

Corte de Apelaciones de Chillán, Escobar con Cencosud Retail S.A. (2014): 16 de junio de 2014, Rol 35-2014, Thomson Reuters CL/JUR/3483/2014.

Corte de Apelaciones de Coyhaique, Ortiz con ABC DIN S.A. (2015): 10 de septiembre de 2015, Rol 14-2015, Identificador Vlex Nº 582306582.

Corte de Apelaciones de Concepción, No se consigna (2015): 28 de septiembre de 2015, Rol 575-2015, Identificador VLex No 583450578.

Corte de Apelaciones de Santiago, Verdejo con Administradora Mall Plaza Vespucio S.A. (2015): 5 de octubre de 2015, Rol 998-2015, Thomson Reuters CL/JUR/5921/2015.

Corte de Apelaciones de Santiago, No se consigna con No se consigna (2015): 15 de diciembre de 2015, Rol 1508-2015, Identificador Vlex Nº 589840898.

Corte de Apelaciones de Valparaíso, No se consigna con No se consigna (2016): 19 de enero de 2016, Rol 641-2015, Identificador Vlex Nº 644752149.

Corte de Apelaciones de Concepción, No se consigna con No se consigna (2016): 16 de marzo de 2016, Rol 634-2015, Identificador Vlex Nº 644198421.

Corte de Apelaciones de Santiago, No se consigna con Cencosud Retail S.A. (2016): 12 de abril de 2016, Rol 30-2016, Identificador Vlex 647006641.

Corte de Apelaciones de Santiago, Muñoz con Cencosud Retail S.A. (2016): 8 de julio de 2016, Rol 650-2016, Thomson Reuters CL/JUR/4844/2016.

Corte de Apelaciones de Santiago, Rainao con Arcos Dorados Restaurantes de Chile Limitada (2016): 3 de agosto de 2016, Rol 748-2016, Thomson Reuters CL/JUR/5481/2016.

Corte de Apelaciones de Antofagasta, Cortez con Hotel Terrado Suites Antofagasta (2016): 9 de septiembre de 2016, Rol 72-2016, Thomson Reuters CL/JUR/7318/2016. 
Corte de Apelaciones de Santiago, Lizama con Lider Domicilio Ventas y Distribución Limitada (2016): 7 de noviembre de 2016, Rol 1273-2016, Thomson Reuters CL/JUR/7350/2016

Corte de Apelaciones de Santiago, Rojas con Cencosud Retail S.A. (2016): 18 de noviembre de 2016, Rol 419-2014, Thomson Reuters CL/JUR/7717/2016.

Corte de Apelaciones de Santiago, Sánchez con Administradora de Supermercados Hiper Limitada (2016): 16 de diciembre de 2016, Rol 1606-2016, Thomson Reuters CL/JUR/9049/2016. 